\title{
'ONCE FOR ALL': THE TENSE OF THE ATONEMENT
}

\section{ROBIN LE POIDEVIN}

University of Leeds

\begin{abstract}
Does a proper understanding of the Atonement - the restoration of mankind's relationship with God as a result of Christ's sacrifice - require a particular conception of time? It has been suggested that it does, and that the relevant conception is a 'tensed' or 'dynamic' one, in which distinctions between past, present and future reflect the objective passage of time. This paper examines two arguments that might be given for that contention, and finds that both may be answered by appeal to the asymmetry of causation. The Atonement leaves us free to think of all times as equally real, as traditionally they are for God.
\end{abstract}

\section{THE FINALITY OF THE ATONEMENT}

Therefore, heavenly Father,

We remember his offering of himself

Made once for all upon the cross;

We proclaim his mighty resurrection and glorious ascension;

We look for the coming of your kingdom,

And with this bread and cup,

We make the memorial of Christ your Son our Lord.

These words from the Communion service ${ }^{1}$ are a reminder of Christ's sacrifice in atonement for the sins of man. And the significant phrase 'once for all' expresses both the uniqueness and the finality of that

${ }^{1}$ The passage is taken from the Alternative Service Book (Church of England 1980: Rite A, p. 132). Compare the thematically corresponding part of the prayer of consecration from the 1559 Book of Common Prayer (preserved in Rite B of the ASB, p. 191): 'Almighty God, our heavenly Father, who of thy tender mercy didst give thine only Son Jesus Christ to suffer death upon the Cross for our redemption; who made there (by his one oblation of himself once offered) a full, perfect, and sufficient sacrifice, oblation, and satisfaction 
atonement. A single act of sacrifice of this kind was sufficient for all time to redeem us. No further sacrifice would be necessary. The temporal import of these words is unmistakable: the death of Christ completes a process in time, and in so doing effects a permanent change in our relationship to God. The words reflect a quite fundamental idea in Christian theology. As Richard A. Holland has pointed out in his study of time and the Incarnation, the notion of completeness and finality is emphasized in plainly temporal terms in scripture:

That the work accomplished in Jesus' earthly life is completed is an essential element of the theological context of the Incarnation. Important passages of Scripture such as Heb 10:12-14 highlight the fact that Christ's earthly mission was accomplished and is now finished: 'But this Man, after he had offered one sacrifice for sins forever, sat down at the right hand of God, from that time waiting till His enemies are made His footstool. For by one suffering he has perfected forever those who are being sanctified. That Christ's work is finished and complete is stated literally in the phrase 'one sacrifice for sins forever', which idea was first conveyed in the very words of Christ as he hung on the cross, 'It is finished.' [John 19:30] It is also made clear in the imagery of Jesus sitting down at the right hand of the Father, signifying that he needed to perform no other work to accomplish the goal of salvation. Additionally, the completion is seen in the scriptural account of the transformed state of the redeemed man. It is found in Ps 103:12, which states, 'As far as the east is from the west, So far has he removed our transgressions from us;' and 2 Cor 5:17, which says 'Therefore, if anyone is in Christ, he is a new creation; old things have passed away; behold, all things have become new. These passages and others indicate a finality: a transformation achieved through the work of Christ that brings about a new standing before God. (Holland 2012: 183-4)

Compare the second of the Thirty-Nine Articles of Religion: '... who truly suffered, was crucified, dead, and buried, to reconcile his Father to us.'

Holland's argument is that this temporal representation of Christ's sacrifice has consequences for our understanding of God's relation to time. For if we conceive of God as timeless, so that all times are equally present to him, then there is no sense in which sin has been permanently removed: 'But if this is so [if, that is, all times are eternally

for the sins of the whole world; and didst institute, and in his holy Gospel command us to continue, a perpetual memory of that his precious death, until his coming again ...' 
present to God], then the important work of atonement has never been fully accomplished. Sin has not been removed; and Christ hanging on the cross is an ever-present feature of God's life' (Holland 2012: 184). Implicit in Holland's argument is that the language of finality, and the conception of atonement it conveys, is not merely temporal, but tensed: our unredeemed state is said to have been consigned to the past. And that in turn implies something about reality, that in some objective sense our unredeemed state is past as a result of Christ's sacrifice. It is this objectively tensed aspect of sin and sacrifice that is incompatible with a timeless God.

My concern in this paper is less with God's relation to time, as the suggestion that the theological understanding of the Atonement requires a certain 'dynamic' view of time itself, namely the view that time's passage is an objective feature of reality, and not merely of our perspective on that reality. Would this be problematic? Arguably, it would, for two reasons. First, it is often suggested that this dynamic conception of time conflicts with modern physics, and in particular the principle of the relativity of simultaneity. If this (admittedly contested) suggestion is correct, then there is a case for supposing Christology also to face a conflict with modern physics. Second, it might be thought that a dynamic conception of the Atonement introduces an internal theological conflict. Even conceding Holland's argument that the Incarnation makes untenable the traditional view of God as timeless, there remains the principle that, in some sense, all times are present to God: that is, the tensed distinctions of past, present and future so crucial to a dynamic conception simply have no meaning for a perfectly rational God. As Spinoza expresses the idea: 'In so far as the mind conceives a thing under the dictate of reason, it will be equally affected, whether the idea be of a thing present, past, or future.' (Ethics, IV. lxii) The relation between time and the Atonement is a matter of no small import.

Here then is my question: does the doctrine of the Atonement contain as an essential element a particular metaphysical view of time? In what follows, I shall examine this 'dynamic' view - or as I shall call it, in more neutral terms, the $A$-theory - in more detail, and consider the theological prospects for a rival view of time's passage, the $B$-theory. ${ }^{2}$ The suggestion that the doctrine of Atonement makes most sense given the A-theory of

2 The theories derive their names from J. E. McTaggart's (1908) distinction between two ways in which we order events in time: the A-series, which runs from the distant past 
time is one I shall compare with a famous argument of Arthur Prior's, that certain of our emotional responses, and relief in particular, are intelligible only when we conceive of time in tensed terms, an argument which subsequent writers have appealed to in support of the A-theory. ${ }^{3}$ I begin, then, with Prior's argument.

\section{PRIOR ON TIME AND EMOTION}

What is now often referred to as the 'old B-theory' of time asserts that tensed expressions, which represent an event or other object as past, present or future, can be translated into tenseless ones. ${ }^{4}$ So, for example, according to the 'token-reflexive' version of this view, an utterance of 'It is now raining' is equivalent in meaning to 'Raining is simultaneous with this utterance' (the 'is' here does not imply temporal presence). 'Now', in other words, is treated as a token-reflexive expression, on a par with 'here' and ' $\mathrm{I}$ '. A related notion is that tensed expressions are incomplete, and require explicit mention of a date to complete them, offering another tenseless analysis of the tensed expression. Against this, Prior pointed out that our natural expressions of relief resist either kind of analysis:

One says, e.g. 'Thank goodness that's over!', and not only is this, when said, quite clear with no date appended, but it says something which it is impossible that any use of a tenseless copula with a date should convey. It certainly doesn't mean the same thing as, e.g. 'Thank goodness the conclusion of that thing is Friday, June 15, 1954', even if it be said then. (Nor, for that matter, does it mean 'Thank goodness the conclusion of that thing is contemporaneous with this utterance.' Why should anyone thank goodness for that?) (Prior 1959: 17)

This much-quoted passage does indeed seem to provide an effective reply to any attempt to explain the meaning of tensed utterance in purely tenseless terms. But does it have a further, metaphysical significance?

to the distant future; and the B-series, which orders events by means of the relations of temporal priority and simultaneity.

${ }^{3}$ See, e.g. Cockburn (1997).

${ }^{4}$ The view is associated with Bertrand Russell, C. D. Broad and Nelson Goodman. The version presented here is closest to the formulation in Broad (1921: 335). Russell (1915: 212) invokes a psychological factor (relation to an experiencing subject), and Goodman (1951) employs dates. The various analyses are critically discussed in Gale (1968): see especially Chapters II and IV. For metaphysical reasons Broad later came to the view that tense could not be eliminated in this way. 
Proponents of the 'new B-theory', which gained currency in the 1980s, pointed out that the irreducibility of tensed expressions to tenseless ones in terms of meaning was entirely compatible with the thesis that the truth-conditions of tensed statements could be given in tenseless terms. ${ }^{5}$ So the assertion that a certain event was past could be made true by the temporal relation between that event and the assertion, in contrast to any objective pastness of the event, even though that relation was not what the speaker intended to convey. An analogy with mental language may be helpful. If physicalism is true, what as a matter of fact makes it true to say that $x$ is in pain is some purely physical fact: a neurophysiological state of $x$ 's brain. But this does not imply that utterances of the kind are equivalent in meaning to some statement about brain states. The analogy has its limits, however. For although, if physicalism is true, the truthmakers of mental state attributions are physical states, we may stop short of insisting that the truth-conditions of mental state ascriptions should be stated in purely physical terms. We might, that is, want to allow that, in some other possible world, such ascriptions are made true by the states of a Cartesian soul, or some such. But the B-theorist, who says, not merely that tensed statements have truth-makers describable in purely tenseless terms, but also that their truth-conditions are so describable, is not making room for worlds in which time passes in reality.

The new B-theory, in short, is a theory about what time is really like, not a theory about what we intend to convey when we say such things as 'We spent Easter in Cornwall last year. It rained.' However, it might be thought that the new B-theory is unstable. ${ }^{6}$ If part of what is conveyed by tensed statements cannot be reduced to tenseless terms, should this not be reflected in the truth-conditions? The B-theorist is obliged to say something about meaning. Here, the distinction between type and token sentences is important. While allowing that the meaning of individual tokens of tensed utterances cannot be conveyed by any tenseless sentences, she wants to say that the meaning of tensed types can be completely conveyed by a tenseless truth-conditional schema. So, for example:

A token $u$ of ' $e$ is past' is true if and only if $e$ is earlier than $u$.

\footnotetext{
${ }^{5}$ See especially Smart (1980), Mellor (1981) and Oaklander (1984).

${ }^{6}$ Just this has been argued by Quentin Smith (1993). His view is that no tenseless statement is adequate to convey the truth-conditions of a tensed statement.
} 
We talk here of a truth-conditional schema, rather than truth conditions, as tensed types, lacking as they do any temporal contexts, do not have truth-values, and so cannot have truth-conditions (i.e. the conditions which would be necessary and sufficient for their truth). The implication of such a schema is that different tokens of a tensed type will have different truth-conditions, and may as a result have different truthvalues. The sense in which tense is irreducible, then, is this: no tenseless statement capable of truth is adequate to convey the conditions under which every token of a given tensed type is true. Tensed statements have a context-sensitivity which tenseless statements lack, and it is this structural difference which makes them non-equivalent. It is also this context sensitivity that we exploit when we use tensed expressions.

A move of this kind gives the lie to the suggestion that, if the B-theory were correct, our tensed language would be systematically misleading, in implying that events are objectively, and not merely perspectivally, past, present or future. If the truth-conditional schema above, and ones like it, capture the conditions under which we can make correct tensed assertions, and our grasp of these conditions are what is required for mastery of tensed expressions, then our ordinary tensed language has no such implication, viz. that there is in reality a passage of time. Nor does it imply that there is no passage of time. For the right-hand side of the biconditional above need not be supposed to capture the most fundamental facts about time. The A-theorist, who believes in the objective passage of time, may also embrace the above schema - but will insist that the fact that $e$ is earlier than $u$ supervenes upon more fundamental facts such as e's being past when $u$ is present.

Let us grant that Prior's 'Thank goodness that's over!' is an effective counterexample to the old B-theory. Is it also an effective counterexample to the new B-theory? An early 'new B-theory' response to Prior's example is Mellor's (1981), according to which we can treat the utterance as consisting of two parts:

'Thank goodness!' and 'That's over'

The first of these is simply an expression of emotion, and is not truthevaluable. The second is a tensed statement, which, since its truthconditions are statable in tenseless terms, does not imply that the event in question is objectively past in some non-perspectival sense. So there is no counterexample to the B-theory here. However, this response will not do. As Murray MacBeath (1983) points out, 'Thank goodness that's 
over' does not plausibly divide in this way, for - as Prior implies - one is thanking goodness for the fact that the event in question is over. And since it is not plausible to suppose one is thanking goodness for the supposedly equivalent tenseless facts, it appears to follow that one is thanking goodness for the fact that the event has really receded into the past, which in turn implies the real passage of time.

It is not enough for the B-theorist to point out that, whatever one might imply by such an expression, it cannot possibly show that time does pass in reality, since any belief may turn out to be mistaken. Such a defence just adds further support to the notion that the B-theory is at odds with our ordinary thought and language. Further, it suggests that a convinced B-theorist cannot, on pain of irrationality, sincerely utter 'Thank goodness that's over!', which would be an unhappy consequence. So there is certainly a challenge here. However, a reason to think that emotional reactions like these do not require any particular metaphysics of time to rationalise them is provided by considering corresponding reactions associated with other kinds of indexical thought. On seeing someone else pick the short straw when some particularly uncongenial task is being allocated, one might utter (or more likely just think) 'Thank goodness that's not me!' But it would be a very peculiar move to take this as intimating a particular metaphysics of the self, on which the world contains a host of ' $\mathrm{I}$ ' facts not reducible to anything expressible in non-indexical language. For there seems no room here to resist the notion that the meaning of assertions containing ' $\mathrm{I}$ ' is wholly given in such truth-conditional schemata as the following:

Any token, uttered/thought by S of 'I am F is true iff S is F.

(I ignore here temporal context-sensitivity. The point is simply that the ' $\mathrm{I}$ ' is eliminable without loss of content.) This gives us reason to suppose that Prior-like examples of 'Thank goodness that's (insert indexical expression)' don't have metaphysical implications. Indeed, it is not at all clear that Prior's original point was that they do. But what, then, rationalises utterances of 'Thank goodness that's over' if not (belief in) the objective passage of time?

Let us suppose that a convinced B-theorist has had an unpleasant experience and is, now entirely understandably, relieved that it has ended. If not too distracted to engage in metaphysical reflection at that moment, she may be aware that the experience is not over in any non-perspectival sense: it is simply earlier than her memory of it. But in a purely 
perspectival sense, it is over. Why is this not enough to justify her relief? For experience is irreducibly perspectival: temporally, spatially and personally perspectival. What she experiences she experiences as happening to her ('to me' as she would put it), as now and as here. That perspective is available to her in a way in which the non-perspectival facts underlying the experience are not. And when she expresses relief she does so in response to that experience. Why should the fact that the experience is a result of perspective do anything to undermine, or make irrational, that expression?

The moral so far, then, is that the personal and emotional importance we attach to things being over neither implies, nor requires for the rationality of such an attachment, that anything is over in the A-theorist's sense of being objectively and non-perspectivally past. But is this moral applicable to our temporal attitude to the Atonement?

\section{A MORAL GRADIENT?}

To rehearse the challenge to the B-theory posed by the Atonement, the general form of argument can be presented as follows:

(1) The Atonement resulted from a final, once-for-all sacrifice for our sins.

(2) For the Atonement to have been final in this sense, our unredeemed state must be objectively past.

(3) The B-theory denies that anything is objectively past.

Therefore:

(4) Our understanding of the significance of the Atonement requires a rejection of the B-theory.

Even if successful, the argument does not establish that the B-theory is in fact false, merely that belief in the doctrine of the Atonement requires a commitment to the A-theory. The B-theorist might object to (3) on the grounds that the theory provides perfectly objective truth-conditions for the truth of such statements as 'Our unredeemed state is past', but it is clear that what 'objectively' means in the context of this argument is 'in a non-perspectival sense. The pastness of our unredeemed state must not merely be a matter of perspective for it to have been truly final.

Could the B-theorist's response to the 'Thank goodness that's over' case be of service here? In other words, perhaps the suspect premise is (2). 
It is enough, that is, for the Atonement to be past from our perspective, since it is its significance for us that matters. We can quite rationally exclaim 'Thank goodness our unredeemed state is past' without having to subscribe to the metaphysical (as opposed to phenomenological) passage of time. But now this response seems quite inadequate for this case. We might indeed feel proper relief that the Atonement has restored our broken relationship with God. But that relief (unlike the relief at the passing of some unpleasant experience) is not simply to do with how things seem to us. The restoration of our relationship with God transcends all experience. So if it is important for our unredeemed state to be objectively over, as opposed to simply being earlier than any given assessment of its state, it seems that this will indeed involve commitment to the A-theory. Nevertheless, (2) is the most contentious premise, and as it is not self-evident, further argument is necessary. We will look at two possible arguments in favour of (2), what we might call 'the moral progress argument', and 'the open future argument' respectively.

The first of these draws attention to the contrast between moral progress and moral regress. Take Christian in Bunyan's The Pilgrim's Progress. He leaves home, despite the entreaties, and eventually insults, of his family, to seek eternal life. But his way to the Celestial City is beset by dangers and temptations: the Slough of Despond, Doubting Castle, the Valley of the Shadow of Death, and many others. He grows in stature as the narrative progresses, becoming ever stronger in resisting the specious reasoning of the various (clearly doomed) characters he meets on the way. His story is one of moral and spiritual progress, from sin to salvation. He thus represents our intended path. Contrast his story with that of one of the darkest of Shakespeare's tragic characters, Macbeth. At the beginning of the play, no-one has a word to say against him, as we hear accounts of his exceptional bravery and loyalty. But the promise of the crown of Scotland leads him to regicide, the first step on a downward path. To make his potion safe, he orders further murders, including that of his former fellow general, Banquo. In the end, he is sick with selfdisgust, but can see no option but to continue: 'I am in blood/Stepped in so far that, should I wade no more, /Returning were as tedious as to go o'er' (Act III, Scene 4). Macbeth's story is one of moral regress and psychological disintegration.

It is perhaps rather obvious that Christian's condition is preferable to Macbeth's, but suppose that there were two individuals, $\mathrm{P}$ and $\mathrm{R}$, such that every stage of moral development in P's life had a counterpart 
in R's life, so that how good or bad $\mathrm{P}$ was at a given stage, $\mathrm{R}$ was in exactly the same condition at some stage in his life. Once we see these stages in order, however, it appears that whereas P's life shows steady improvement, R's shows steady deterioration. Even though in terms of overall goodness and badness they are comparable, we would say that P's life was objectively better than R's. However, the A-theorist may insist that, on the B-theory view, all we have in each case is a moral gradient. The various stages of moral character form an order. To say that P's life is one of progress and R's one of regress is (for the B-theorist) a perspectival way of thinking of things. A hill may be described as 'uphill' or 'downhill' only from the perspective of someone looking in one direction rather than another. In itself, the hill is merely a gradient. To explain the fact that P's life is objectively (and not merely perspectivally) better than R's we need to be able to describe P's as an objectively improving life and R's an objectively deteriorating one. To make it entirely explicit: P's morally inferior state is objectively in the past, whereas for $\mathrm{R}$ it is the morally superior state that is objectively in the past. And that, of course, is only something that A-theorist can say.

Thanks to the Atonement, our fallen state is in the past, so the life of mankind overall (despite some fallen souls) is one of progress, not regress.

Let us now turn to the second argument in favour of (2).

\section{THE OPEN FUTURE AND THE METAPHYSICS OF ATONEMENT}

So far, we have simply been concerned with the question of the passage of time. But there is arguably a more fundamental issue which bears on the significance of the Atonement, and that is the ontological asymmetry between past and future. Indeed, one powerful reason to think that the passage of time is a non-perspectival matter is that only thus can we preserve the objective difference between past and future. There is, as we might put it, a fact of the matter as to what has happened: the past is part of reality (though obviously not of present reality), and is what makes objectively true our past-tensed statements. In contrast, there is no fact of the matter as to what will happen. The future is not part of reality, and cannot make true our future-tensed statements. Those future-tensed statements that are true, if there are any, are made true by present (or past) fact. And one might argue further that this ontological openness 
of the future is required if we are to be genuinely free to determine the future (though here, admittedly, the fallacies of fatalism may lurk). More generally, we might connect the openness of the future with the possibility of genuine causation: what a cause does is to bring its effect into reality. ${ }^{7}$

Suppose that the future is open in this sense: that it consists simply in a range of possibilities, no one of which is yet actual. Room is then made for a metaphysical conception of the transformative effect of the Atonement. For during the time of our fallen state and broken relationship with God, the Atonement is still in the future, and not part of reality. Once Christ's sacrifice is made, the Atonement becomes part of reality, and God is reconciled to humanity for all time - and here we might read 'for all time', or 'once for all', as looking backwards as well as forwards. That is, the reconciliation covers the past as well as the present and future. No part of time is unaffected by the transformation. (Despite appearances, this does not imply that the past has been changed in the sense that intrinsic features of past times have now been made other than what they were: that would be impossible. Rather, past individuals now stand in a different relation to God as a result of the Atonement.)

The crucial question, then, in respect of our fallen state at any given time, is whether the Atonement is or is not part of reality at that time.

On the B-theory, there is no such ontological asymmetry between past and future. This follows from the fact that 'past' and 'future' are, on this theory, purely relative, perspectival terms. 'The past' simply refers to times earlier than the time of speaking; 'the future' to later times. With no passage of time, there is no scope for any change in what is real. For 'real' is not similarly perspectival. ${ }^{8}$ On this theory, then, the Atonement, if real at any time, is real with respect to all time: its reality does not change over time. It seems that we are left with a choice between two uncongenial possibilities: (i) since the Atonement is at all times part of reality, and since the Atonement is sufficient for restoring our relationship with God for all time, then at no time is God unreconciled to humanity; (ii) since the sin that broke our relationship with God is at all times part of reality, and since that sin separates us from God, then at no time are we reconciled to God. To recall Holland's remark: 'the important work of

7 This entirely natural view is perhaps the biggest challenge to the B-theory, but exploring it here would take us too far afield.

8 This natural assumption is sometimes challenged, however. See, e.g., Dorato (1995). 
atonement has never been fully accomplished. Sin has not been removed; and Christ hanging on the cross is an ever-present feature of God's life' (2012: 184). Either way, there is no change from fallen to redeemed state for man. Man is forever - or never - reconciled with God. If we take the first of these options, the difference the Atonement makes can then only be conceived in counterfactual rather than temporal terms: if the Atonement had not occurred, man would at no time be reconciled to God. If we take the second, then the Atonement makes no difference. We then have a further argument which suggests that the passage of time is essential to our understanding of the Atonement, for only if time passes can we make room for the ontological asymmetry between past and future that makes the Atonement a genuinely novel part of reality when it occurs.

That concludes the case for the A-theory's account of the Atonement. It is time now to hear the other side.

\section{A QUESTION OF CAUSALITY}

To summarise the story so far:

The discussion of Prior's 'thank goodness that's over' case was intended to show that the B-theorist's denial of the real passage of time is entirely compatible with the irreducibly tensed nature of a significant part of our mental lives, our emotional lives in particular. For our tensed beliefs about the world are, for the B-theorist, a reflection of our perspective on the tenseless facts which constitute the truth-conditions for those beliefs. No revision to our ordinary ways of thinking and talking is necessary. Our emotional responses to tensed beliefs (such as the relief we feel when we believe that some unpleasant experience is over) can continue to be seen as rational, given that our experience of the world is perforce temporally (and personally and spatially) perspectival. But the B-theorist cannot straightforwardly carry this strategy over to the Atonement, because the significance of the Atonement is not simply an experiential one. We may, indeed, feel relief on being told that our relationship with God has been restored, but that is just incidental. The important thing is that our relationship really has been restored, independently of any belief to that effect. Two arguments were presented in favour of an A-theoretic account of the Atonement:

The moral progress argument: the B-theory can allow only that our relationship with God exhibits a moral gradient. Our fallen state 
precedes our reconciled state: there is no further fact of progress from fallen to reconciled state.

The open future argument: for Christ's sacrifice to transform our relationship to God in time, it must become part of reality - that is, it was once unreal, but then became real, and this in turn requires an objective asymmetry between past and future: the past is real, the future not. But the B-theory cannot allow such an asymmetry.

I want to suggest now that the B-theorist can respond to both of these arguments by appeal to the asymmetry of causation.

The moral progress argument implies that the B-theorist can offer an account only of temporal order, but not of temporal direction. There is no sense, that is, that events run from earlier to later, rather than vice versa, because that can only be conferred by the direction of the passage of time. But the B-theorist is not obliged to concede that the direction of time has to be viewed in such dynamic terms. There is an important asymmetry between earlier and later times in that what happens at earlier times can causally affect what happens at later times, but not vice versa. The direction of time, in other words, is grounded in the direction of causation. ${ }^{9}$ So there is an objective, and not merely perspectival difference between the Pilgrim's story of moral progress, and Macbeth's story of moral regress. For the Pilgrim, the state of being burdened by sin and the tendency to succumb to temptation is causally antecedent to the state of being saved. For Macbeth, loyalty, courage and friendship are causally antecedent to betrayal, murder, cynicism and psychological disintegration. These objective causal differences, which make neither explicit nor implicit appeal to time's passage, are sufficient for us to recognise the pattern of Pilgrim's life as superior to Macbeth's. Similarly, the case of mankind, where the fallen state is causally antecedent to the reconciled state, is, by virtue of that causal direction, one of progress.

The reply to the open future argument takes a similar form, but is prefaced by a counter-challenge: what metaphysical mechanism does the A-theorist suppose is involved in Atonement? This is not fully answered by offering one of the various moral accounts of the Atonement, for example the ransom, satisfaction or penal substitution theories. Such an account might answer the question: 'In what way does

\footnotetext{
${ }^{9}$ The B-theorist is not committed to a causal theory of time-order, but that account of time order can do a great deal of explanatory work, grounding not only the direction of time but also asymmetries in our temporal experience. See Mellor (1981), (1998).
} 
Christ's sacrifice bring about atonement for our sins?' That is, of course, an urgent question, but it doesn't immediately settle the further, and perhaps somewhat more abstract, question, 'What kind of effect does that sacrifice have?' The first question is a moral question, and raises the tricky issue of how the sacrifice of an innocent being can change our own moral standing in the eyes of God. That is not a question I have tried to address here because it seems to me largely orthogonal to the topic of this paper: the relationship between the Atonement and the metaphysics of time. ${ }^{10}$ But the second question (at least, as I intend it) is a metaphysical question. To focus it somewhat: is the effect of Christ's sacrifice a causal or a non-causal one? If the former, then it is at least intelligible, in that we can relate it to the way in which our own actions have effects. But if the mechanism by which Christ's sacrifice brings about the restoration of our relationship with God is causal, then it is not Christ's sacrifice simply being part of reality that constitutes Atonement, but rather the causal consequences of that sacrifice. And since there is no backwards causation, those consequences can only appear after the sacrifice, not beforehand. So even though, on the B-theory, all times are equally real, this does not imply that there is no change in our relationship to God over time. If, then, we opt for a causal account, we are not faced with a choice between God being at all times reconciled to humanity, and God being at all times unreconciled to humanity. The fallen state of man is brought to an end by the sacrifice of Christ, the causal (and therefore temporally later) consequence of which is reconciliation with God. No appeal to an open future is necessary.

But what of the earlier suggestion that the Atonement somehow works backwards, redeeming mankind for all time, past as well as future? If backwards causation is impossible, then does this not require a noncausal notion of the consequences of Christ's sacrifice? This thought, however, is misguided. There is a sense in which the Atonement works backwards and a sense in which it does not. The sense in which it does is to make it the case now that God is reconciled with all of humanity past, present and future humanity. This is entirely compatible with the

${ }^{10}$ This needs some qualification. On one model of the Atonement, namely the moral exemplar account, on which Christ saves us by giving us an example of a perfect life, it is evident that the mechanism whereby we are saved (which requires an active response to Christ's life) cannot work backwards in time, as it is straightforwardly a causal process. See, e.g. Graham (2010) for a discussion of this and other accounts of Atonement. 
effects of Christ's sacrifice being later than their cause. The sense in which it does not is the sense in which the past is somehow changed intrinsically, so that it is now - but not previously - the case that past humanity was already reconciled to God, prior to Christ's sacrifice. But this is not a sense we want anyway, since this kind of changing the past is, as we have already noted, impossible.

We have critically examined two arguments for the suggestion that an understanding of the Atonement requires a view of time as objectively passing. Though plausible, neither argument stands up to scrutiny. The B-theorist, who denies objective passage, can account for the relevant phenomena (the idea of humanity progressing from fallen to redeemed state, and the asymmetry between before and after Christ's sacrifice) by appeal to a causal theory of time order. Now, I do not simply presume that these arguments are exhaustive. There may well be other considerations. But I challenge those who favour an A-theoretic conception of the Atonement to produce them. I also concede that causal theories of time order are not uncontroversial. But they do not actually conflict with the A-theory, so the B-theorist cannot be accused of begging the question in appealing to them. (Indeed, it is not obvious that this objection would be warranted even if there were a conflict with the A-theory, for if the A-theorist is entitled to offer an explanation of the relevant asymmetries in A-theoretic terms, the B-theorist is entitled to offer a rival account.)

This conclusion should be congenial to those who take God to be indifferent to tensed distinctions, and who suppose that for him all times are of equal intrinsic significance. The Atonement, I suggest, gives us no reason to disagree with Spinoza's dictum 'In so far as the mind conceives a thing under the dictate of reason, it will be equally affected equally, whether the idea be of a thing present, past, or future.'11

\section{REFERENCES}

Broad, C. D. 1921. 'Time', in J. Hastings (ed.), Encyclopaedia of Religion and Ethics (Edinburgh: T\&T Clark), Vol. XII, pp. 334-45

Church of England. 1980. The Alternative Service Book (Colchester: William Clowes, London: SPCK, Cambridge: Cambridge University Press)

${ }^{11}$ This passage is quoted by Cockburn (1997), who proceeds to explore the difficulties posed by it by emotional responses of the kind exemplified by Prior's 'thank goodness' case. 
Cockburn, David. 1997. Other Times; Philosophical Perspectives on Past, Present and Future (Cambridge: Cambridge University Press)

Dorato, Mauro. 1995. Time and Reality: Spacetime Physics and the Objectivity of Temporal Becoming (Bologna: CLUEB)

Gale, Richard M. 1968. The Language of Time (London: Routledge and Kegan Paul)

Graham, Gordon. 2010. 'Atonement', in Charles Taliaferro and Chad Meister (eds), The Cambridge Companion to Christian Philosophical Theology (Cambridge: Cambridge University Press), pp. 124-35

Goodman, Nelson. 1951. The Structure of Appearance, Boston Studies in the Philosophy and History of Science, Vol. 53

Holland, Richard A. 2012. God, Time and Incarnation (Oregon: Wipf and Stock)

MacBeath, Murray. 1983. 'Mellor's Emeritus Headache', Ratio, 25: 81-8

McTaggart, J. E. 1908. 'The Unreality of Time', Mind, 18: 457-84

Mellor, D. H. 1981. Real Time (Cambridge: Cambridge University Press)

1998. Real Time II (London: Routledge)

Oaklander, L. Nathan. 1984. Temporal Relations and Temporal Becoming: a Defense of a Russellian Theory of Time (Lanham: University Press of America)

Prior, A. N. 1959. 'Thank goodness that's over', Philosophy, 34: 12-17

Russell, Bertrand. 1915. 'On the Experience of Time', The Monist, 25: 212-33

Smart, J. J. C. 1980. 'Time and Becoming', in Peter van Inwagen (ed.), Time and Cause: Essays Presented to Richard Taylor (Dordrecht: D. Riedel), pp. 3-15

Smith, Quentin. 1993. Language and Time (Oxford: Oxford University Press)

Spinoza, Benedictus de. 1989. Ethics, trans. by Andrew Boyle, revised G. H. R. Parkinson (London: Dent) 